\title{
Incomplete Seating of Modular Dual Mobility Metal Liner within a Hemispherical Acetabular Shell
}

\author{
Murukan Babua, Philip K Thomasa, Paul K Jose ${ }^{a}$ \\ a. Senior Consultant and Head of Department of Orthopaedics, Rajagiri Hospital, Aluva, Kerala India
}

Published on $1^{\text {st }}$ June 2020

\begin{abstract}
A 59-year-old male, diagnosed with advanced arthritis of left hip underwent total hip arthroplasty using a modular dual mobility with metal liner. Post-operative radiographs there was suspicion of incomplete seating of the metal liner inferiorly. The patient was reoperated the next day which confirmed the incomplete seating. The metal liner seating was corrected which was confirmed by intra operative visualization and fluoroscopy. Post-operative radiographs showed complete seating of the liner. Periodic follow ups were uneventful. Incomplete seating of dual mobility metal liner especially at the inferior part, though seldom reported is a possible complication which can lead to early failure.
\end{abstract}

Key Words: Modular Dual Mobility, Metal Liner, Total Hip Replacement, Malseating

\section{INTRODUCTION}

$\mathrm{T}$ The dual mobility cup was developed with a goal to decrease the dislocation rate by associating two articular surfaces: one with a larger diameter situated between a metallic cup and a polyethylene insert, and the other one with a smaller diameter situated between the femoral head and the polyethylene insert.'

Only one case of seating problem of dual mobility metal liner on trident acetabular shell has been reported so far worldwide. $^{2}$

Seating malaligment issues associated with various acetabular systems have been well documented in multiple studies, but almost all were involving ceramic acetabular shell liners. ${ }^{3-9}$

This case report describes one similar seating malalignment involving dual mobility metal liner and Trident acetabular shell.

\section{CASE HISTORY}

59 year old male, presented with pain and difficulty in walking since 9 years. He had a history of childhood fall followed by limping for some months. A diagnosis of secondary arthritis of left hip was made, for which total hip arthroplasty was performed (Figure 1).

Through posterior approach, acetabulum was serially reamed upto 44 and a $46 \mathrm{~mm}$ (Stryker Trident PSL, Michigan, U.S.) HA cluster shell was impacted (Figure 2). One cancellous screw was put in the postero superior

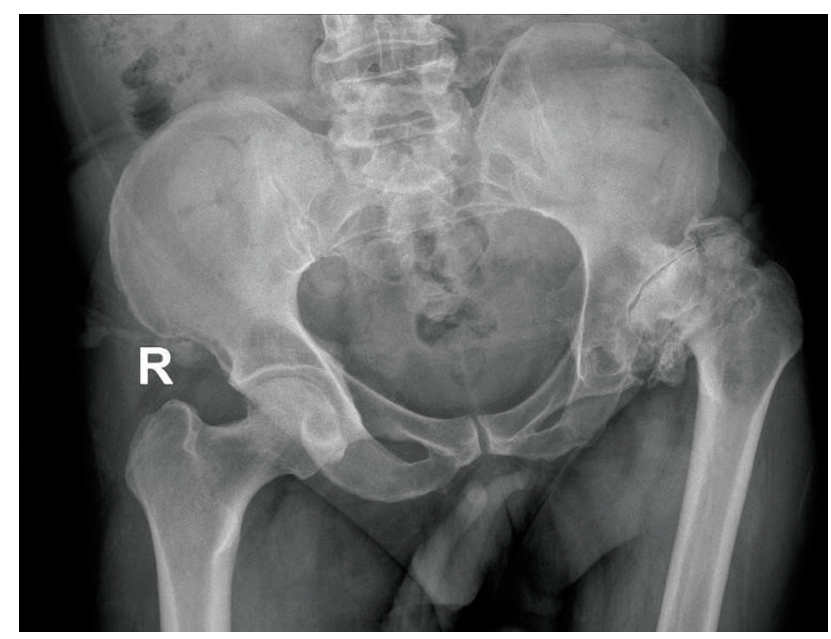

Figure 1. X ray Pelvis - Advanced Osteoarthritis left hip

Cite this article as: Babu M, Thomas PK, Jose PK. Incomplete Seating of Modular Dual Mobility Metal Liner within a Hemispherical Acetabular Shell. KJOrth. 2020 Jun 1;33(01):30-3.

\section{Corresponding Author:}

Dr Philip K Thomas, MS ortho, Consultant, Department of Orthopaedics, Rajagiri Hospital, Aluva, Kerala, India.

Mobile: 9895244507 E-mail: drphiliportho@gmail.com

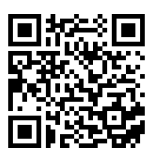

\section{Access this Article Online \\ Scan this QR Code}

https://doi.org/10.52314/kjo.2020.v33i01.13 


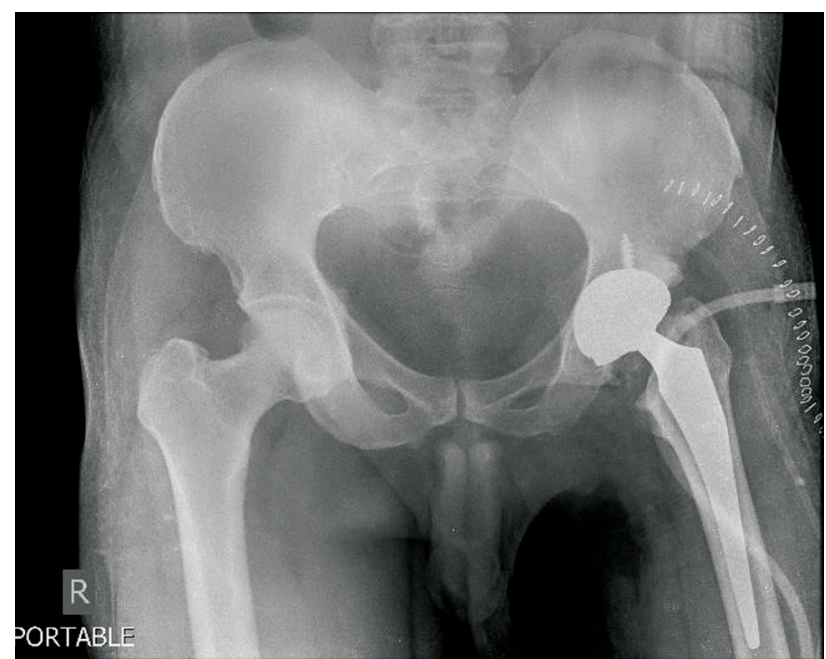

Figure 2. Postoperative $\mathrm{x}$ ray pelvis AP demonstrating incomplete seating of the metal liner inferiorly

quadrant. dual mobility metal liner of corresponding size (ID $38 \mathrm{~mm}$, alpha code D) was impacted into the shell. Liner was visualized to be seated properly all along the edges. Femoral neck cut taken one finger breath above lesser trochanter. Box cut taken, canal identified with a straight reamer. Femoral broaching done sequentially up to size 2 after trial reduction and checking of stability original implantation done using Accolade TMZF uncemented stem $132^{\circ}$ neck angle V40 hip stem size 2, neck length $30 \mathrm{~mm}$, stem length $115 \mathrm{~mm}$. dual mobility X3 poly insert for dual mobility metal liner ID $22.2 \mathrm{~mm}, 38 \mathrm{~mm}$ OD size 38D, femoral head offset -2 , OD $22.2 \mathrm{~mm}$ (V40 TM head) were put, joint reduced and assessed for stability and movements. No signs of instability or impingement was noted and wound was closed. Post-operative $\mathrm{x}$ ray was taken on the next day, which showed suspicion of incomplete seating of dual mobility metal liner on the acetabular shell.

As the epidural catheter was in place, the patient was taken to operating room, after informed consent. On exposure of

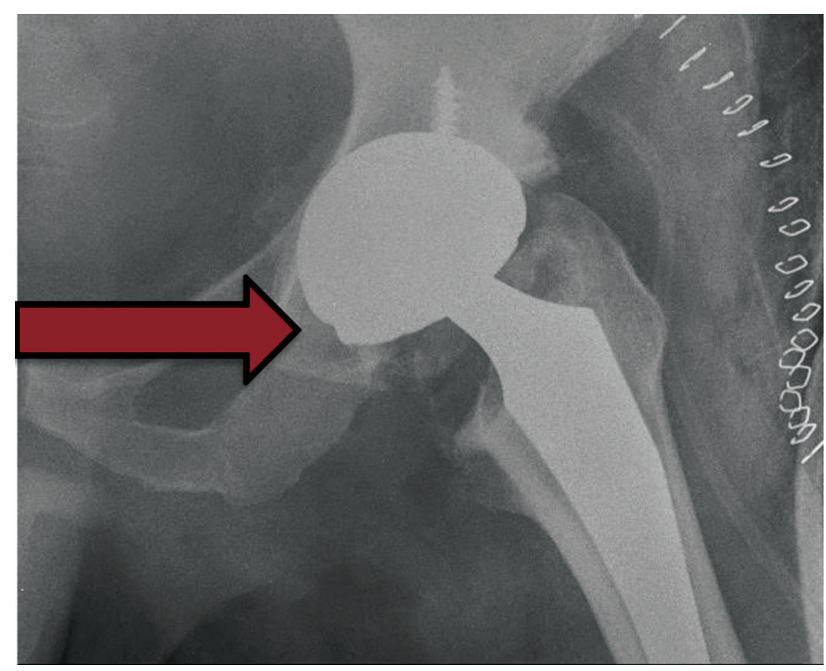

Figure 3. Magnified view - demonstrating incomplete seating of the metal liner inferiorly

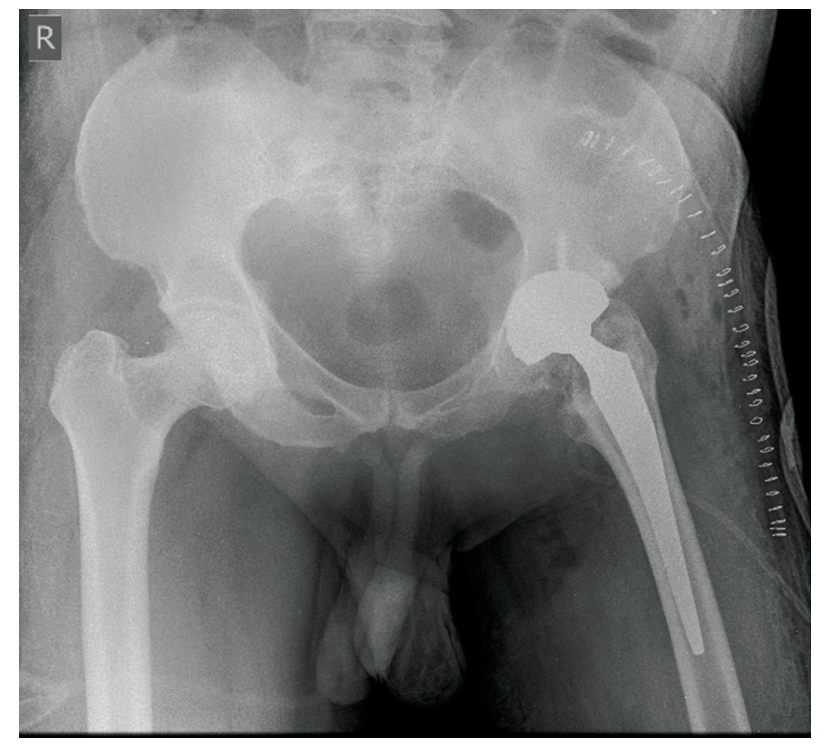

Figure 4. X ray after correction

the hip joint, we noticed that superior part of metal liner was seated but there was incomplete seating of the metal liner in the inferior part. However, no component damage was noted. The liner was detached and reinserted, visually confirming the seating superiorly as well as inferiorly. This was further confirmed with intraoperative fluoroscopy

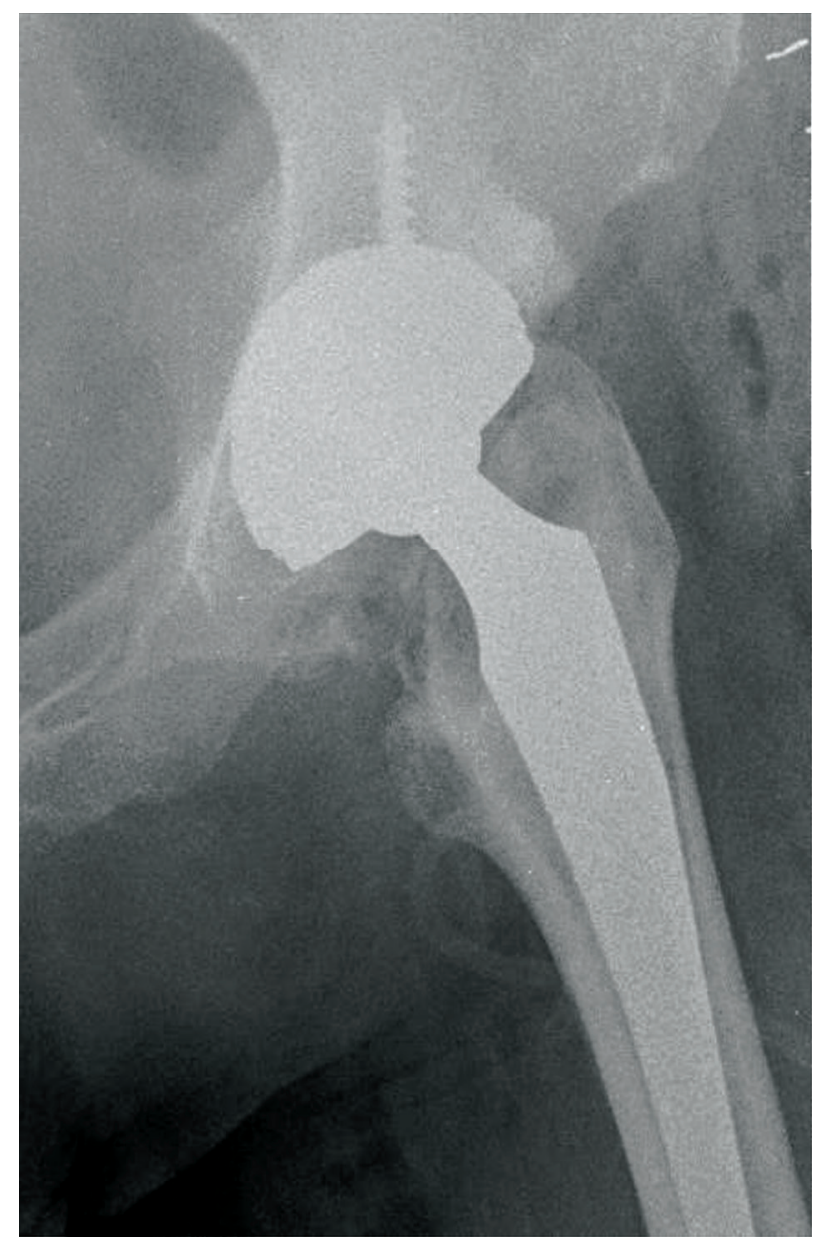

Figure 5. Magnified view after correction 


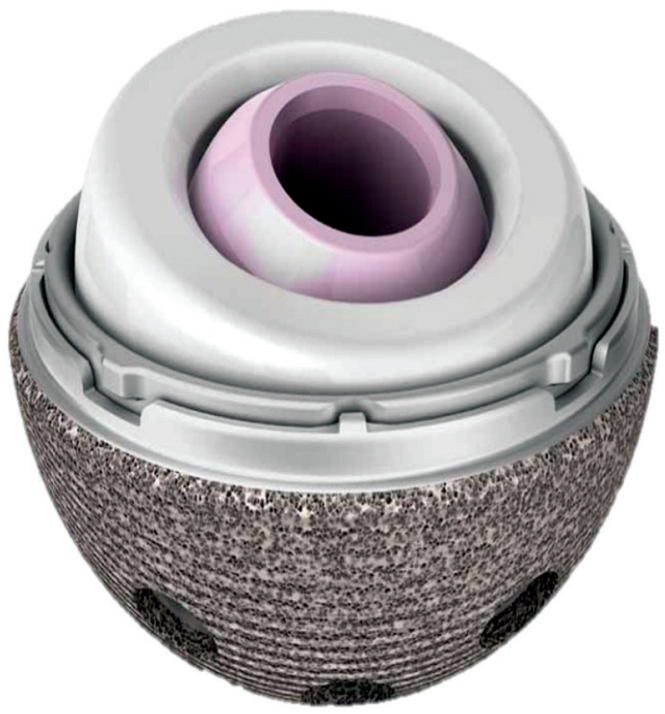

Figure 6. Dual mobility system - Acetabular shell with metal liner and poly insert with femoral head

(Figures 3, 4, 5). The patient was mobilized as per standard protocol from the very next day. At six month follow up, he was walking unassisted with no radiographic abnormality.

\section{DISCUSSION}

Dual mobility is designed to help prevent dislocation and aim to achieve stability, longevity in primary or revision total hip arthroplasty. ${ }^{10}$

Dual mobility is based on the dual mobility principle with two points of articulation. dual mobility bearings combines two well-known concepts in THA: ${ }^{10}$

The Charnley low friction arthroplasty (LFA) prosthesis has demonstrated clinically and radiologically that smaller diameter heads produce lower torque force in the acetabular shell and consequently less wear. ${ }^{17,18}$

The large head concept from McKee-Farrar recognizes that a large diameter bearing is inherently more stable than a smaller diameter head. ${ }^{17}$

The dual mobility system comprises a thin polished cobalt chromium acetabular metal liner that engages the acetabular shell via a taper and articulates with a large diameter highly crosslinked polyethylene (X3) head that encapsulates chrome cobalt or ceramic femoral head. ${ }^{19}$ Dual mobility offers stability with its large head and low friction design. It has a three dimensional posterior dislocation distance at 26 degrees of pelvic tilt, a 59\% greater jump height with dual mobility compared to a conventional THA with a $36 \mathrm{~mm}$ head and $81 \%$ greater jump height compared to competitive hard-on-hard bearing. ${ }^{20}$

Dislocation rates of dual mobility systems has been reported to be low with only one study reporting two early dislocations and three dislocations after ten years in a series of 668 cases (Figure 6). ${ }^{1}$

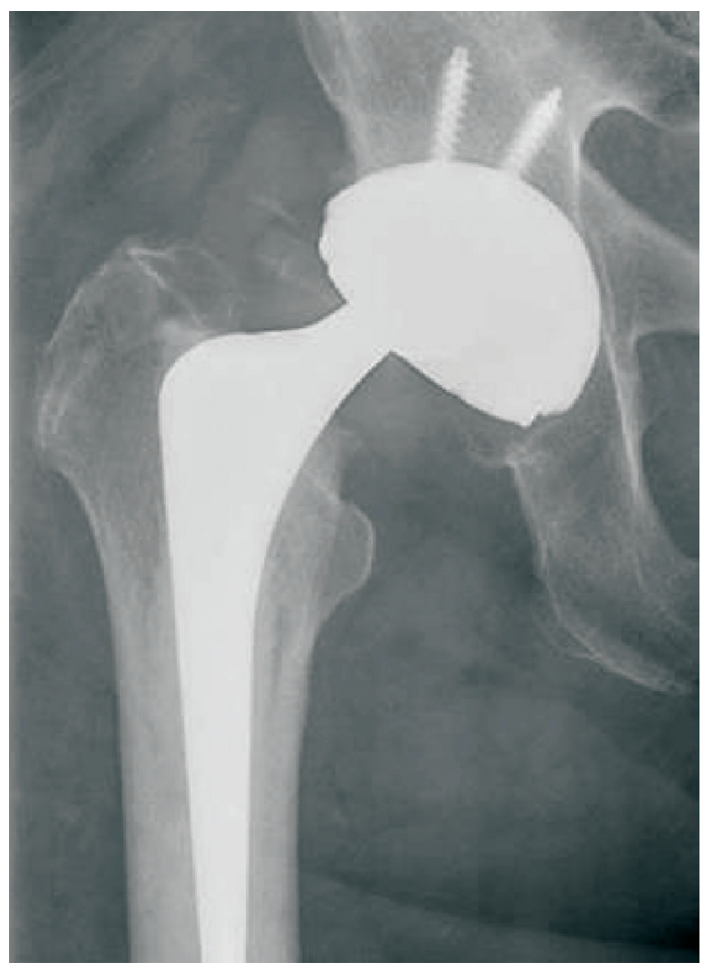

Figure 7. Intra prosthetic dislocation - femoral head is eccentric in position inside the acetabular cup

The dual mobility couple mates a fixed femoral head to a mobile polyethylene (PE) liner, which articulates with a smooth metal shell. Thus, there is an inner, small diameter articulation, with a capture mechanism between the head and the liner, and a larger, unconstrained, outer articulation. Because there is an additional bearing interface compared with fixed bearing THA, dual mobility THA can suffer a unique failure mechanism known as an intraprosthetic dislocation (IPD), in which the inner prosthetic femoral head disengages from the outer PE liner. IPD is irreducible by closed means and always require surgical management and dual mobility bearing component revision. ${ }^{12}$ Missing this type of dislocation can result in acetabular component damage because the femoral head (metallic or ceramic) articulates directly with the smooth metallic shell, leading to acetabular damage that may necessitate shell revision. ${ }^{13,14}$

Food and Drug Administration (FDA) approved trident acetabular shell in 2003, and the system is being widely used around with multiple liners. The shell is made of titanium with hydroxyapatite coating. ${ }^{15}$

The dual mobility metal liner has a tapered locking mechanism, similar to the trident ceramic liner. In cases of malseating of ceramic liner in trident shell, it has been hypothesized that the shells deform on press fit to the acetabulum. $^{3-9}$ This results in malalignment of the liner locking tabs, leading to malseating of the liner.

Studies of metal backed ceramic liners with this acetabular component, Langdown et al. reported $16.8 \%$ of 117 liners were improperly seated while studies by Howcroft et al., 
Carvajal Alba et al., and Miller et al. have reported similar findings. $3,4,7,9$

Modern thinner acetabulum shells may be at greater risk for this type of deformation compared to traditionally thicker acetabular shells. ${ }^{6}$

Markel D et al demonstrated the acetabular shell deformation caused by press fit, resulting in an average of $0.17 \mathrm{~mm}$ pinch deformity. ${ }^{6}$ A study of Depuy Pinnacle (Warsaw, IN) acetabular shells also demonstrated a comparable incidence and degree of deformation. ${ }^{16}$

Intraoperative factors which predispose to incomplete seating. The taper of the liner may be damaged by the insertion technique resulting in deformations in both the liner and shell resulting in seating failure. Soft tissue interposition and sub-sequent locking mechanism failure is also attributed as a potential cause for incomplete seating. ${ }^{3,4}$

For a posterior approach, the inferomedial aspect of the liner is difficult to assess and the presence of loose soft tissue or malseating of the inferior liner and may go unnoticed.

To prevent the risk of malseating, surgeons should do intraoperative visual checks of the inferior part of acetabular shell and liner either physically or by fluoroscopy. Prior to insertion, complete visualization of the cup and removal of potential loose tissue is important. Both the shell and liner can be checked with an instrument to attempt to dislodge the component or with the use of radiographs. The use of a single intraoperative AP x-ray can detect inferior malseating which is the most likely missed position during the posterior approach, however this can fail to pick up potential anterior or posterior malseating (Figure 7). ${ }^{5}$

\section{SUMMARY}

This case report shows that incomplete seating of the dual mobility metal acetabular liner within the acetabular shell is a possible complication. Precaution should be taken with liner placement and correction should be done post operatively if suspected to prevent failure.

\section{END NOTE}

\section{Author Information}

1. Dr Murukan Babu, MS Ortho, D Ortho Senior Consultant and Head of Department of Orthopaedics, Rajagiri Hospital, Aluva, Kerala India

2. Dr Philip K Thomas, MS ortho, Consultant Department of Orthopaedics, Rajagiri Hospital, Aluva, Kerala, India.

3. Dr Paul K Jose, MS Ortho, Consultant, Department of Orthopaedics, Rajagiri Hospital, Aluva, Kerala, India.

Conflict of Interest: None declared

\section{REFERENCES}

1. Vielpeau C, Lebel B, Ardouin L, Burdin G, Lautridou C. The dual mobility socket concept: experience with 668 cases. Int Orthop. $2011 \mathrm{Feb} ; 35(2): 225-30$.

2. Eskildsen SM, Olsson EC, Del Gaizo DJ. Canted seating of the Stryker Modular Dual Mobility liner within a Trident hemispherical acetabular shell. Arthroplast Today. 2016 Mar;2(1):19-22.

3. Carvajal Alba JA, Schiffman ED, Scully SP, Parvataneni HK Incomplete seating of a metal-backed alumina liner in ceramic-onceramic total hip arthroplasty. Orthopedics. 2010 Jan;33(1):15.

4. Langdown AJ, Pickard RJ, Hobbs CM, Clarke HJ, Dalton DJN, Grover ML. Incomplete seating of the liner with the Trident acetabular system: a cause for concern? J Bone Joint Surg Br. 2007 Mar;89(3):291-5.

5. Iwai S, Kabata T, Maeda T, et al. Using intraoperative radiography to detect incomplete seating of Trident acetabular system ceramic liners. Eur Orthop Traumatol 2013; 4:21

6. Markel D, Day J, Siskey R, Liepins I, Kurtz S, Ong K. Deformation of metal-backed acetabular components and the impact of liner thickness in a cadaveric model. Int Orthop. 2011 Aug;35(8):1131-7.

7. Miller AN, Su EP, Bostrom MPG, Nestor BJ, Padgett DE. Incidence of Ceramic Liner Malseating in Trident ${ }^{\circledR}$ Acetabular Shell. Clin Orthop Relat Res. 2009 Jun;467(6):1552-6.

8. McAuley JP, Dennis DA, Grostefon J, Hamilton WG. Factors affecting modular acetabular ceramic liner insertion: a biomechanical analysis. Clin Orthop Relat Res. 2012 Feb;470(2):402-9.

9. Howcroft DWJ, Qureshi A, Graham NM. Seating of ceramic liners in the uncemented trident acetabular shell: is there really a problem? Clin Orthop Relat Res. 2009 Oct;467(10):2651-5.

10. Philippot R, Camilleri JP, Boyer B, Adam P, Farizon F. The use of a dual-articulation acetabular cup system to prevent dislocation after primary total hip arthroplasty: analysis of 384 cases at a mean follow-up of 15 years. International Orthopaedics (SICOT). 2009 Aug;33(4):927-32.

11. De Martino I, Triantafyllopoulos GK, Sculco PK, Sculco TP. Dual mobility cups in total hip arthroplasty. World J Orthop. 2014 Jul 18;5(3):180-7.

12. Waddell BS, De Martino I, Sculco T, Sculco P. Total Hip Arthroplasty Dislocations Are More Complex Than They Appear: A Case Report of Intraprosthetic Dislocation of an Anatomic Dual-Mobility Implant After Closed Reduction. Ochsner J. 2016;16(2):185-90.

13. Joseph Schirmers MD, Ryan Horazdovsky MD, Scott Marston MD. Early Intraprosthetic Dislocation of Dual-Mobility Total Hip Arthroplasty Implant Following Attempted Closed Reduction: A Case Report. ReconRev [Internet]. 2015 [cited 2021 Feb 5];5(2).

14. Mohammed R, Cnudde P. Severe metallosis owing to intraprosthetic dislocation in a failed dual-mobility cup primary total hip arthroplasty. J Arthroplasty. 2012 Mar;27(3):493.e1-3.

15. Acetabular System | Stryker [Internet]. [cited 2021 Mar 16].

16. Squire M, Griffin WL, Mason JB, Peindl RD, Odum S. Acetabular component deformation with press-fit fixation. J Arthroplasty. 2006 Sep;21(6 Suppl 2):72-7.

17. Philippot R, Camilleri JP, Boyer B, Adam P, Farizon F. The use of a dual-articulation acetabular cup system to prevent dislocation after primary total hip arthroplasty: analysis of 384 cases at a mean follow-up of 15 years. Int Orthop. 2009 Aug;33(4):927-32.

18. Wroblewski BM, Siney PD, Fleming PA. The principle of low frictional torque in the Charnley total hip replacement. J Bone Joint Surg Br. 2009 Jul;91(7):855-8.

19. Philippot R, Boyer B, Farizon F. Intraprosthetic Dislocation: A Specific Complication of the Dual-mobility System. Clin Orthop Relat Res. 2013 Mar;471(3):965-70.

20. Stryker Test Report: RD-10-073. Range of motion and two and three dimensional jump distance of the Modular Dual Mobility Insert. 2010 